• 研究报告・

\title{
长江上游支流南广河的鱼类多样性及资源现状
}

\author{
代梦梦 ${ }^{1}$ 杨 坤 $^{2} \quad$ 黎 树 $^{1}$ 王小东 $^{1}$ 宋昭彬 $1,3^{*}$ \\ 1 (四川大学生命科学学院四川省濒危野生动物保护生物学重点实验室, 成都 610065) \\ 2 (西华师范大学生态研究院, 四川南充 637009) \\ 3 (四川大学生命科学学院生物资源与生态环境教育部重点实验室, 成都 610065)
}

\begin{abstract}
摘要：南广河是长江上游一级支流，为全面了解该河流的鱼类多样性，作者于2017年11月至2018年9月在南广河 干流及支流 28 个采样点进行了 6 次调查, 共采集鱼类64种, 隶属于 5 目13科48属, 其中四川省重点保护鱼类有鲇鲤 (Percocypris pingi)和岩原鲤(Procypris rabaudi) 2种, 长江上游特有鱼类17种, 列入 《中国脊椎动物红色名录》的濒 危和易危的鱼类有 9 种。南广河现有分布鱼类以小型种类为主，宽鳍鯔(Zacco platypus)和鲤(Cyprinus carpio)为优势 种。南广河鱼类多样性总体较高, Margalef丰富度指数、Shannon-Wiener多样性指数、Simpson优势度指数及Pielou 均匀度指数分别为 $6.57 、 3.10 、 0.93 、 0.74$; 中游河段的鱼类种类和数量较丰富, 分别占渔获物总种类和总数量的 65.63\%和 $28.98 \%$; 支流镇舟河的鱼类种类和数量也较丰富, 分别占 $37.50 \%$ 和 $20.48 \%$ 。南广河不同河段的鱼类种类 组成具有明显差异, 大坝建设和过度捕捞可能影响了鱼类分布并导致其资源量下降。
\end{abstract}

关键词: 南广河; 物种多样性; 鱼类资源; 优势种

\section{Fish diversity and resource status in the Nanguang River, a tributary of upper Yangtze River}

\author{
Mengmeng Dai ${ }^{1}$, Kun Yang ${ }^{2}$, Shu Li ${ }^{1}$, Xiaodong Wang ${ }^{1}$, Zhaobin Song ${ }^{1,3^{*}}$ \\ 1 Sichuan Key Laboratory of Conservation Biology on Endangered Wildlife, College of Life Sciences, Sichuan University, \\ Chengdu 610065 \\ 2 Institute of Ecology, China West Normal University, Nanchong, Sichuan 637009 \\ 3 Key Laboratory of Bio-Resources and Eco-Environment of Ministry of Education, College of Life Sciences, Sichuan \\ University, Chengdu 610065
}

\begin{abstract}
Nanguang River is a tributary of upper Yangtze River that provides important resources and food to various communities. To understand the current status of fish diversity within Nanguang River, we sampled the river and its primary tributaries six times from November 2017 to September 2018. A total of 64 fish species were collected, two of which (Percocypris pingi and Procypris rabaudi) are protected fish in Sichuan Province, 17 species were endemic to the upper Yangtze River, and 9 were listed as endangered or vulnerable species in Red List of China's Vertebrates. The most dominant fish were small in size, of which Zacco platypus and Cyprinus carpio were most dominant. Additionally, the Nanguang River fish community possess considerable diversity based on Margalef species richness index, Shannon-Wiener diversity index, Simpson dominance index, and Pielou evenness index values. While there are obvious differences in fish composition across different reaches of the Nanguang River, dam construction and overfishing may have considerably impacted fish distribution and fish resources, the results of which our investigation presents.
\end{abstract}

Key words: Nanguang River; species diversity; fish resources; dominant species

南广河是长江上游一级支流，古称符黑水、符 江，发源于云南省威信县大雪山北麓，流经云南省
威信县, 四川省珙县、筠连县和高县, 在宜宾市南 广镇汇入长江。该河干流全长约 $222 \mathrm{~km}$, 流域面积 
约 $4,800 \mathrm{~km}^{2}$, 主要支流有宋江河、巡司河、镇舟河、 洛亥河等。南广河流经云贵高原与四川盆地过渡区 域, 地形复杂多样, 珙县石碑乡以上为上游河段, 山高坡陡, 水流湍急; 石碑乡至高县为中游河段, 山间多冲积槽坝，水量增多，水流渐缓；高县以下 为下游河段, 属盆地边缘丘陵区, 河谷逐渐开阔, 水体较深, 水流缓慢(宜宾市志编纂委员会, 2010)。 南广河河道蜿蜒曲折, 河流水量丰富, 为水生生物 及鱼类提供了多种栖息生境。

迄今为止，南广河干流上已建成月江、来复、 油罐口、孝儿、两河口、石板滩、上罗、罗渡、石 碑、石梯等水电站, 支流上建设的小型水电站也较 多, 电站建设引起的水文情势改变和河道阻隔对鱼 类资源和分布等有明显的影响(原居林等, 2009)。历 史上南广河的鱼类资源非常丰富，根据20世纪90年 代的调查, 南广河有鱼类 90 余种(丁瑞华, 未发表资 料)。2012年，吴波等(2014)在南广河四川境内的干 流河段仅采集到鱼类32种，并发现渔业资源明显衰 退, 指出修建水电站、过度捕捞和水体污染是主要 原因。但是, 由于调查点设置有限, 调查范围仅涉 及四川境内的南广河干流河段, 且渔获物的数量较 少, 可能未反映南广河流域的鱼类资源状况。因此, 全面调查南广河干、支流的鱼类资源，对该流域鱼 类多样性保护具有积极意义, 也为科学评价水电站 建设对鱼类资源的影响提供一些价值参考。

\section{材料与方法}

\section{1 样本采集}

本次调查在南广河干流及主要支流共设置28 个采样点, 其中, 干流设置18个采样点(M1-M18), 4条一级支流共设置10个采样点(T1-T10)(图1，表1), 基本覆盖了南广河干、支流不同河段及生境。调查 时间为2017年11月，2018年1、3、5、7、9月，每次 调查持续约 $10 \mathrm{~d}$ 。干流河段鱼类采集以雇请渔民在 指定采样点放置刺网捕捞为主, 地笼为辅。支流鱼 类采集则以刺网、地笼捕捞为主, 辅以小型背包式 电鱼机捕捞(经渔业主管部门批准)。同时, 走访渔 民、沿河居民, 以了解南广河历史上的鱼类种类组 成及鱼类资源变化情况等。刺网网长主要为 $30 \mathrm{~m}$ 、 $40 \mathrm{~m} 、 50 \mathrm{~m}$, 网高为 $1-2 \mathrm{~m}$, 网目大小主要为 $2 \mathrm{~cm}$ 、 $3 \mathrm{~cm} 、 5 \mathrm{~cm}$, 每个采样点放置 2 张网, 采样时间约为 $12 \mathrm{~h}$; 地笼规格为长 $10 \mathrm{~m}$ 、宽 $0.30 \mathrm{~m}$ 、高 $0.25 \mathrm{~m}$, 网目

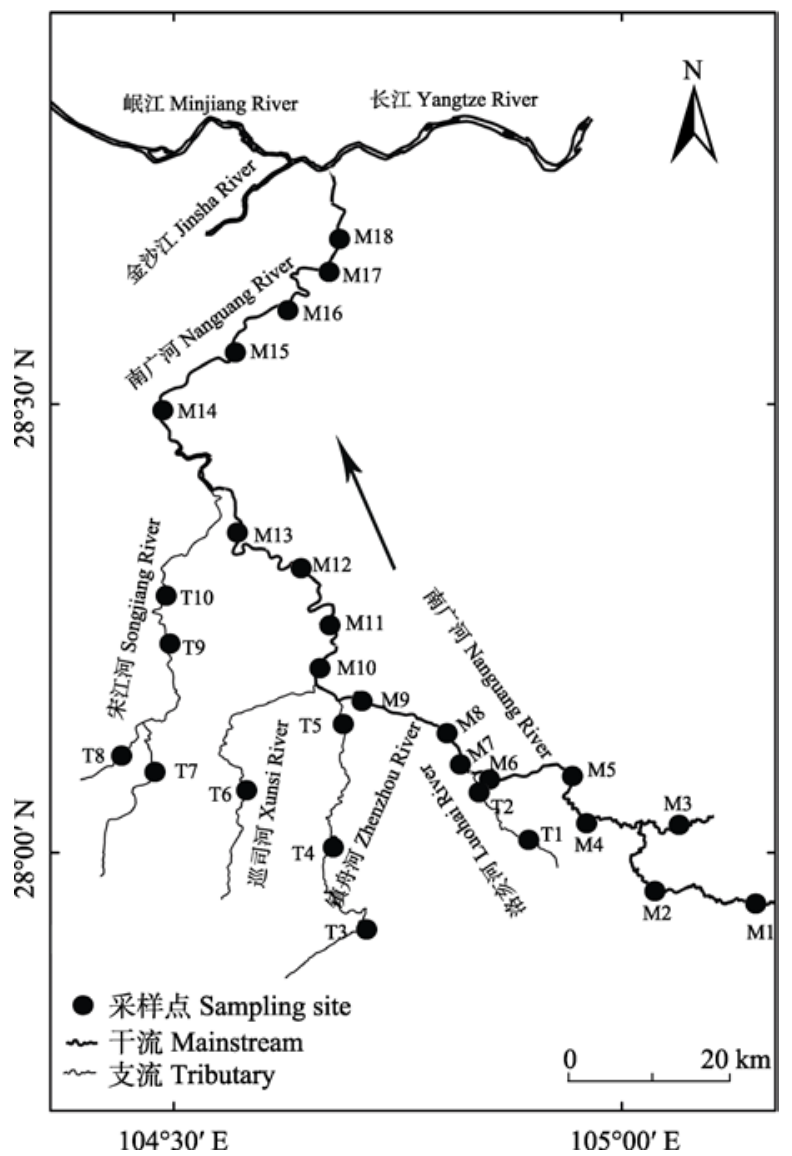

图1 南广河鱼类资源调查采样点。符号代表含义见表1。 Fig. 1 Sampling sites of fish investigation in the Nanguang River. Symbol meanings are shown in Table 1.

为 $5 \mathrm{~mm}$, 每个采样点放置 4 个, 采样时间约 $12 \mathrm{~h}$; 电 捕时逆河流方向在单程长约 $500 \mathrm{~m}$ 的河段采样约 $45 \mathrm{~min}$ 。采集到的样本参考《四川鱼类志》(丁瑞华, 1994)、《中国动物志 - 硬骨鱼纲 - 鲤形目 (中卷)》 (陈宜瑜, 1998)、《中国动物志・硬骨鱼纲・ 鲤形目 (下卷)》(乐佩琦, 2000)、《中国动物志・硬骨鱼纲・鲇 形目》(禇新洛等, 1999)等进行鉴定, 并测量全长(精 确至1 mm)、体长(精确至1 mm)、体重(精确至0.01 g), 统计个体数量。对现场难以确定种类的样本先拍 照、测量, 然后用 $10 \%$ 的福尔马林或 $95 \%$ 的乙醇浸泡 固定，带回实验室进一步鉴定。鱼类种类的濒危等级 依据《中国脊椎动物红色名录》(蒋志刚等, 2016), 学 名依据Kottelat (2013)和Fishbase (www.fishbase.org)。

\section{2 数据分析}

(1)群落优势种

采用Pinkas相对重要性指数(index of relative importance, IRI)(Pinkas et al, 1971)划定南广河流域 鱼类群落的优势种。计算公式为: 
表1 南广河鱼类资源调查采样点信息

Table 1 Information of sampling sites for fish investigation in the Nanguang River

\begin{tabular}{|c|c|c|c|c|}
\hline 河流 River & 河段 Reach & 采样点(代码) Sampling site (Code) & 纬度 Latitude $(\mathrm{N})$ & 经度 Longitude (E) \\
\hline \multirow{18}{*}{$\begin{array}{l}\text { 干流 } \\
\text { Mainstream }\end{array}$} & \multirow{5}{*}{$\begin{array}{l}\text { 上游 } \\
\text { Upstream }\end{array}$} & 高田乡 Gaotian Township (M1) & $27^{\circ} 57^{\prime}$ & $105^{\circ} 09^{\prime}$ \\
\hline & & 罗布乡 Luobu Township (M2) & $27^{\circ} 57^{\prime}$ & $105^{\circ} 02^{\prime}$ \\
\hline & & 旧城镇 Jiucheng Town (M3) & $28^{\circ} 02^{\prime}$ & $105^{\circ} 04^{\prime}$ \\
\hline & & 观斗乡 Guandou Township (M4) & $28^{\circ} 02^{\prime}$ & $104^{\circ} 58^{\prime}$ \\
\hline & & 石碑乡 Shibei Township (M5) & $28^{\circ} 06^{\prime}$ & $104^{\circ} 57^{\prime}$ \\
\hline & \multirow{7}{*}{$\begin{array}{l}\text { 中游 } \\
\text { Midstream }\end{array}$} & 罗渡电站库区 Reservoir of Luodu Hydropower Station (M6) & $28^{\circ} 05^{\prime}$ & $104^{\circ} 51^{\prime}$ \\
\hline & & 罗渡大桥 Luodu Bridge (M7) & $28^{\circ} 06^{\prime}$ & $104^{\circ} 49^{\prime}$ \\
\hline & & 上罗镇 Shangluo Town (M8) & $28^{\circ} 08^{\prime}$ & $104^{\circ} 48^{\prime}$ \\
\hline & & 共腾村 Gongteng Village (M9) & $28^{\circ} 11^{\prime}$ & $104^{\circ} 42^{\prime}$ \\
\hline & & 沐滩乡 Mutan Township (M10) & $28^{\circ} 13^{\prime}$ & $104^{\circ} 40^{\prime}$ \\
\hline & & 孝儿镇 Xiaoer Town (M11) & $28^{\circ} 16^{\prime}$ & $104^{\circ} 40^{\prime}$ \\
\hline & & 趃滩乡 Zantan Township (M12) & $28^{\circ} 19^{\prime}$ & $104^{\circ} 38^{\prime}$ \\
\hline & \multirow{6}{*}{$\begin{array}{l}\text { 下游 } \\
\text { Downstream }\end{array}$} & 文江镇 Wenjiang Town (M13) & $28^{\circ} 22^{\prime}$ & $104^{\circ} 34^{\prime}$ \\
\hline & & 贾村 Jia Village (M14) & $28^{\circ} 30^{\prime}$ & $104^{\circ} 29^{\prime}$ \\
\hline & & 来复镇 Laifu Town (M15) & $28^{\circ} 33^{\prime}$ & $104^{\circ} 34^{\prime}$ \\
\hline & & 大窝镇 Dawo Town (M16) & $28^{\circ} 36^{\prime}$ & $104^{\circ} 37^{\prime}$ \\
\hline & & 月江镇 Yuejiang Town (M17) & $28^{\circ} 39^{\prime}$ & $104^{\circ} 40^{\prime}$ \\
\hline & & 南广镇 Nanguang Town (M18) & $28^{\circ} 41^{\prime}$ & $104^{\circ} 41^{\prime}$ \\
\hline \multirow{10}{*}{$\begin{array}{l}\text { 支流 } \\
\text { Tributary }\end{array}$} & \multirow{2}{*}{$\begin{array}{l}\text { 洛亥河 } \\
\text { Luohai River }\end{array}$} & 洛亥镇 Luohai Town (T1) & $28^{\circ} 01^{\prime}$ & $104^{\circ} 54^{\prime}$ \\
\hline & & 黄桷村 Huangjue Village (T2) & $28^{\circ} 04^{\prime}$ & $104^{\circ} 51^{\prime}$ \\
\hline & \multirow{3}{*}{$\begin{array}{l}\text { 镇舟河 } \\
\text { Zhenzhou River }\end{array}$} & 大雪山镇 Daxueshan Town (T3) & $27^{\circ} 55^{\prime}$ & $104^{\circ} 43^{\prime}$ \\
\hline & & 镇舟镇 Zhenzhou Town (T4) & $28^{\circ} 01^{\prime}$ & $104^{\circ} 41^{\prime}$ \\
\hline & & 维新镇 Weixin Town (T5) & $28^{\circ} 09^{\prime}$ & $104^{\circ} 41^{\prime}$ \\
\hline & 巡司河 Xunsi River & 武德乡 Wude Township (T6) & $28^{\circ} 05^{\prime}$ & $104^{\circ} 35^{\prime}$ \\
\hline & \multirow{4}{*}{$\begin{array}{l}\text { 宋江河 } \\
\text { Songjiang River }\end{array}$} & 双腾镇 Shuangteng Town (T7) & $28^{\circ} 06^{\prime}$ & $104^{\circ} 29^{\prime}$ \\
\hline & & 塘坝乡 Tangba Township (T8) & $28^{\circ} 07^{\prime}$ & $104^{\circ} 27^{\prime}$ \\
\hline & & 羊田乡 Yangtian Township (T9) & $28^{\circ} 14^{\prime}$ & $104^{\circ} 30^{\prime}$ \\
\hline & & 罗场镇 Luochang Town (T10) & $28^{\circ} 17^{\prime}$ & $104^{\circ} 29^{\prime}$ \\
\hline
\end{tabular}

$$
I R I=(N+W) \times F \times 10^{4}
$$

式中, $N$ 为某一种类的尾数占总尾数的百分比, $W$ 为 某一种类的重量占总重量的百分比, $F$ 为某一种类 出现的频率。定义IRI $\geq 1,000$ 的为优势种; $1,000>$ $I R I \geq 100$ 的为常见种; $100>I R I \geq 10$ 的为一般种; $I R I<10$ 的为偶见种(程济生和俞连福, 2004; 熊飞 等, 2014)。

(2)鱼类多样性

采用 Margalef种类丰富度指数 $(D)$ (Margalef, 1958)、Shannon-Wiener多样性指数 $\left(H^{\prime}\right)$ (Shannon \& Wiener, 1949)、Simpson优势度指数 $(F)$ (Simpson, 1949)和Pielou均匀度指数 $\left(J^{\prime}\right)$ (Pielou, 1975)分析南广 河流域的鱼类群落多样性，相关计算公式如下:

$$
\begin{aligned}
& D=(S-1) / \ln N \\
& H^{\prime}=-\sum P_{i} \ln \left(P_{i}\right) \\
& F=1-\sum\left(P_{i}\right)^{2} \\
& J^{\prime}=H^{\prime} / \ln S
\end{aligned}
$$

式中, $S$ 为渔获物中的物种数, $N$ 为渔获物中个体总 数, $P_{i}$ 为第 $\mathrm{i}$ 个物种的个体数占总个体数的比例。

\section{结果}

\section{1 鱼类种类组成}

调查期间共采集到鱼类64种，隶属于5目 13 科 48属(附录1), 其中, 鲤形目鱼类最多, 为4科 38 属 47 种, 占总种数的 $73.44 \%$; 其次是鲇形目, 为 4 科 5 属 12 种，占总种数的 $18.75 \%$; 鲇形目为 3 科 3 属 3 种，占 
总种数的 $4.69 \%$; 鳗鳕目和合鳃鱼目都仅有 1 科 1 属 1 种, 各占 $1.56 \%$ 。在不同科中, 鲤科鱼类最多, 共36 种, 占总种数的 $56.25 \%$; 其次是鲿科, 为 8 种, 占 $12.50 \%$; 鳅科 5 种，占 $7.81 \%$; 条鳅科和爬鳅科均 3 种, 各占 $4.69 \%$; 鲇科2种, 占 $3.13 \%$; 鳗鲡科、针头 鯔科、鮡科、合鳃鱼科、真鲇科、鰕虎鱼科及鳢科 均为 1 种，各占 $1.56 \%$ 。

采集鱼类中, 长江上游特有鱼类17种，包括短 体副 鳅 (Homatula potanini)、长薄 鳅 (Leptobotia elongata)、四川华鳊(Sinibrama taeniatus)、高体近 红鲌(Ancherythroculter kurematsui)等。四川省重点 保护鱼类 2 种, 分别为鲇鲤(Percocypris pingi)和岩 原鲤(Procypris rabaudi)。列入 《中国脊椎动物红色 名录》的濒危物种(EN) 3种, 分别为鳗鲡(Anguilla japonica)、鲈鲤和昆明裂腹鱼(Schizothorax grahami); 易危物种 (VU) 6 种, 分别为中华沙鳅 (Sinibotia superciliaris)、长薄鳅、厚领鲂(Megalobrama pellegrini)、齐口裂腹鱼(Schizothorax prenanti)、岩原鲤 和白缘鮃(Liobagrus marginatus)。

\section{2 渔获物组成}

调查期间共采集鱼类14,666尾，总重量276.03 $\mathrm{kg}$ 。其中, $I R I>1,000$ 的优势种为宽鯺鱲 (Zacco platypus)和鲤(Cyprinus carpio), 其数量和重量占比 之和分别达到 $18.29 \%$ 和 $27.18 \%$; IRI $>100$ 的常见种 有鲫 (Carassius auratus)、麦穗鱼 (Pseudorasbora parva)、高体鳑鲏(Rhodeus ocellatus)、切尾拟鲿 (Tachysurus truncatus)等17种鱼类, 其数量和重量 占比之和分别达到 $66.97 \%$ 和 $44.91 \% ; I R I<10$ 的偶 见种有 28 种, 其数量和重量占比之和仅为 $2.62 \%$ 和 $9.20 \%$ (表2)。17种长江上游特有鱼类中有 13 种都为 偶见种, 长吻鯔(Tachysurus dumerili)、乌鳢(Channa argus)、白甲鱼(Onychostoma simum)、鲢(Hypophthalmichthys molitrix)、岩原鲤和鲈鲤等中、小型经 济鱼类也多为偶见种。渔获物中大多数个体的规格 较小, 如宽鯺鱲(7.27 g)、麦穗鱼(5.03 g)、高体鳑鲏 (2.63 g)、切尾拟鲿(15.32 g)、马口鱼(Opsariichthys bidens)(14.56 g)、瓦氏黄㸚鱼(Tachysurus vachellii) (17.30 g)、唇䱻(Hemibarbus labeo)(36.11 g)和蛇鮈 (Saurogobio dabryi)(13.46 g)等鱼类的平均体重均 较小。

本次调查在南广河干流共采集鱼类56种 8,783 尾, 占渔获物总数量的 $59.89 \%$; 4 条支流共采集鱼类
41种 5,883 尾，占渔获物总数量的 $40.11 \%$ 。干流上游 至河源河段共采集31种2,950尾; 中、下游河段各采 集 42 和 43 种, 分别占渔获物总种类数的 $65.63 \%$ 和 $67.19 \%$, 但中游河段采集数量最多 $(4,250$ 尾), 占渔 获物总数量的 $28.98 \%$, 表明南广河中游河段鱼类资 源较为丰富。中游支流镇舟河采集鱼类24种3,004 尾, 分别占渔获物总种类和总数量的 $37.50 \%$ 和 $20.48 \%$, 是鱼类资源较为丰富的一条支流, 其次为 巡司河和宋江河, 采集样本数量分别占渔获物总数 量的 $8.55 \%$ 和 $7.95 \%$ 。中上游支流洛亥河虽采集到鱼 类22种, 但数量较少, 仅 459 尾, 占渔获物总数量的 $3.13 \%$ (表3)。

\section{3 鱼类多样性}

基于不同河段渔获物显示, 南广河干流Margalef种类丰富度指数为3.75-5.70, 支流为2.10-3.43; 干流Shannon-Wiener多样性指数为2.60-3.14, 支流 为 1.91-2.30; 干流Simpson优势度指数为 $0.88-0.94$, 支流为 0.79-0.86; 干流 Pielou 均匀度指数为 0.77-0.84, 支流为 $0.64-0.74$ 。可见，南广河干流河 段鱼类多样性高于支流, 其中下游河段多样性最高, 上游河段较低(图2)。

基于全年渔获物显示, 南广河Margalef种类丰 富度指数为6.57, Shannon-Wiener多样性指数为 3.10 , Simpson优势度指数为 0.93 , Pielou均匀度指数为 0.74。可见, 南广河鱼类种类丰富度及多样性总体 较高。

\section{4 鱼类分布特点}

南广河不同河段的鱼类组成具有一定的差异 性, 分布于干流下游河段的鱼类主要有子陵吻鰕虎 鱼(Rhinogobius giurinus)、大眼鲊(Siniperca knerii)、 鲫、㱩(Hemiculter leucisculus)、唇 䱻、趐嘴鲌(Culter alburnus)和鲤等; 分布于干流中游河段的鱼类主要 有高体鳑鲏、麦穗鱼、宽鯺鱲、乐山小鳔鮈(Microphysogobio kiatingensis)、切尾拟鲿、棒花鱼 (Abbottina rivularis)、唇鮥和蛇鮈等; 干流上游至源 头河段的鱼类主要为宽鯺鱲、瓦氏黄颡鱼、蛇鮈、 贝氏高原鳅(Triplophysa bleekeri)、红尾副鳅(Homatula variegata)、泉水鱼(Pseudogyrinocheilus prochilus)和齐口裂腹鱼等。支流宋江河、巡司河、镇舟 河的鱼类组成相似, 多为宽鯺鱲、麦穗鱼、切尾拟 魭、红尾副鳅、短体副鳅、泥鳅(Misgurnus anguillicaudatus)、高体鳑鲏等小型鱼类，但在宋江河、 
表2 南广河鱼类的相对重要性指数

Table 2 The index of relative importance of fish species in the Nanguang River

\begin{tabular}{|c|c|c|c|c|c|}
\hline $\begin{array}{l}\text { 种类 } \\
\text { Species }\end{array}$ & $\begin{array}{l}\text { 数量百分比 } \\
\text { Percentage of } \\
\text { number (\%) }\end{array}$ & $\begin{array}{l}\text { 重量百分比 } \\
\text { Percentage of } \\
\text { weight (\%) }\end{array}$ & $\begin{array}{l}\text { 出现频率 } \\
\text { Frequency of } \\
\text { occurrence }\end{array}$ & $\begin{array}{l}\text { 相对重要性指数 } \\
\text { Index of relative } \\
\text { importance (IRI) }\end{array}$ & $\begin{array}{l}\text { 优势类型 } \\
\text { Dominant type }\end{array}$ \\
\hline 宽鯺鱲 Zacco platypus & 17.65 & 6.82 & 0.71 & $1,747.45$ & $\mathrm{D}$ \\
\hline 鲤 Cyprinus carpio & 0.65 & 20.37 & 0.54 & $1,125.78$ & $\mathrm{D}$ \\
\hline 鲫 Carassius auratus & 2.48 & 8.89 & 0.75 & 852.53 & $\mathrm{C}$ \\
\hline 麦穗鱼 Pseudorasbora parva & 9.29 & 2.48 & 0.71 & 840.62 & $\mathrm{C}$ \\
\hline 高体鳑鲏 Rhodeus ocellatus & 9.95 & 1.39 & 0.64 & 728.73 & $\mathrm{C}$ \\
\hline 切尾拟鲿 Tachysurus truncatus & 4.64 & 3.77 & 0.75 & 630.83 & $\mathrm{C}$ \\
\hline 马口鱼 Opsariichthys bidens & 3.71 & 2.87 & 0.54 & 352.39 & $\mathrm{C}$ \\
\hline 瓦氏黄颡鱼 Tachysurus vachellii & 3.80 & 3.49 & 0.46 & 338.42 & $\mathrm{C}$ \\
\hline 唇䱻 Hemibarbus labeo & 2.20 & 4.23 & 0.46 & 298.45 & $\mathrm{C}$ \\
\hline 短须领须鮈 Gnathopogon imberbis & 4.38 & 1.21 & 0.50 & 279.59 & $\mathrm{C}$ \\
\hline 棒花鱼 Abbottina rivularis & 5.28 & 1.67 & 0.39 & 272.95 & $\mathrm{C}$ \\
\hline 红尾副鳅 Homatula variegata & 3.91 & 1.28 & 0.50 & 259.44 & $\mathrm{C}$ \\
\hline 乐山小鳔鮈 Microphysogobio kiatingensis & 4.83 & 1.27 & 0.39 & 239.44 & $\mathrm{C}$ \\
\hline 蛇鮈 Saurogobio dabryi & 3.61 & 2.58 & 0.32 & 199.23 & $\mathrm{C}$ \\
\hline 子陵吻鰕虎鱼 Rhinogobius giurinus & 2.93 & 0.63 & 0.54 & 190.79 & $\mathrm{C}$ \\
\hline 泉水鱼 Pseudogyrinocheilus prochilus & 1.66 & 2.62 & 0.43 & 183.77 & $\mathrm{C}$ \\
\hline 翅嘴鮊 Culter alburnus & 0.38 & 5.05 & 0.25 & 135.87 & $\mathrm{C}$ \\
\hline 短体副鳅 Homatula potanini & 2.82 & 0.91 & 0.36 & 133.23 & $\mathrm{C}$ \\
\hline 泥鳅 Misgurnus anguillicaudatus & 1.11 & 0.55 & 0.61 & 101.08 & $\mathrm{C}$ \\
\hline 光泽黄颡鱼 Tachysurus nitidus & 1.77 & 1.15 & 0.29 & 83.56 & G \\
\hline 黄颞鱼 Tachysurus fulvidraco & 0.45 & 1.22 & 0.46 & 77.76 & G \\
\hline 大眼鳜 Siniperca knerii & 1.03 & 2.53 & 0.21 & 76.35 & G \\
\hline 鲇 Silurus asotus & 0.20 & 1.19 & 0.46 & 64.28 & G \\
\hline 草鱼 Ctenopharyngodon idella & 0.07 & 2.88 & 0.21 & 63.11 & G \\
\hline 福建纹胸鮡 Glyptothorax fokiensis & 1.69 & 0.62 & 0.25 & 57.84 & G \\
\hline 粗唇鮠 Tachysurus crassilabris & 0.49 & 0.71 & 0.46 & 55.98 & G \\
\hline 贝氏高原鳅 Triplophysa bleekeri & 2.17 & 0.40 & 0.18 & 45.79 & G \\
\hline 齐口裂腹鱼 Schizothorax prenanti & 0.70 & 1.63 & 0.18 & 41.64 & G \\
\hline 南方鲇 Silurus meridionalis & 0.16 & 2.60 & 0.14 & 39.40 & G \\
\hline 花䱻 Hemibarbus maculatus & 0.51 & 0.89 & 0.25 & 34.92 & G \\
\hline 四川华吸鱾 Sinogastromyzon szechuanensis & 1.13 & 0.15 & 0.25 & 31.99 & G \\
\hline 大鳍鳠 Hemibagrus macropterus & 0.27 & 0.99 & 0.25 & 31.54 & G \\
\hline 大鳞副泥鳅 Paramisgurnus dabryanus & 0.29 & 0.29 & 0.36 & 20.83 & G \\
\hline 中华倒刺鲃 Spinibarbus sinensis & 0.06 & 0.84 & 0.18 & 16.08 & G \\
\hline 黑尾㛑 Hemiculter tchangi & 0.80 & 0.45 & 0.11 & 13.45 & G \\
\hline 中华沙鳅 Sinibotia superciliaris & 0.32 & 0.16 & 0.21 & 10.21 & G \\
\hline 云南光唇鱼 Acrossocheilus yunnanensis & 0.31 & 1.03 & 0.07 & 9.63 & $\mathrm{R}$ \\
\hline 其他 Others & 2.30 & 8.17 & 1.50 & 62.13 & $\mathrm{R}$ \\
\hline
\end{tabular}

D: 优势种; C: 常见种; G: 一般种; R: 偶见种。

D, Dominant species; C, Common species; G, General species; R, Rare species. 
表3 南广河不同河段渔获物组成

Table 3 Composition of fish collected from different reaches of the Nanguang River

\begin{tabular}{llllll}
\hline $\begin{array}{l}\text { 河流 } \\
\text { River }\end{array}$ & 河段 & 种数 & 种数百分比 & 数量 & 数量百分比 \\
流 Mainstream & Number of species & Percentage of species (\%) & Sample size & Percentage of quantity (\%) \\
\hline & 上游 Upstream & 31 & 48.44 & 2,950 & 20.11 \\
& 中游 Midstream & 42 & 65.63 & 4,250 & 28.98 \\
& 下游 Downstream & 43 & 67.19 & 1,583 & 10.79 \\
& 小计 Total & 56 & 87.50 & 8,783 & 59.89 \\
支流 Tributary & 洛亥河 Luohai River & 22 & 34.38 & 459 & 3.13 \\
& 镇舟河 Zhenzhou River & 24 & 37.50 & 3,004 & 20.48 \\
& 巡司河 Xunsi River & 16 & 25.00 & 1,254 & 8.55 \\
& 宋江河 Songjiang River & 21 & 32.81 & 1,166 & 7.95 \\
& 小计 Total & 41 & 64.06 & 5,883 & 40.11 \\
\hline
\end{tabular}

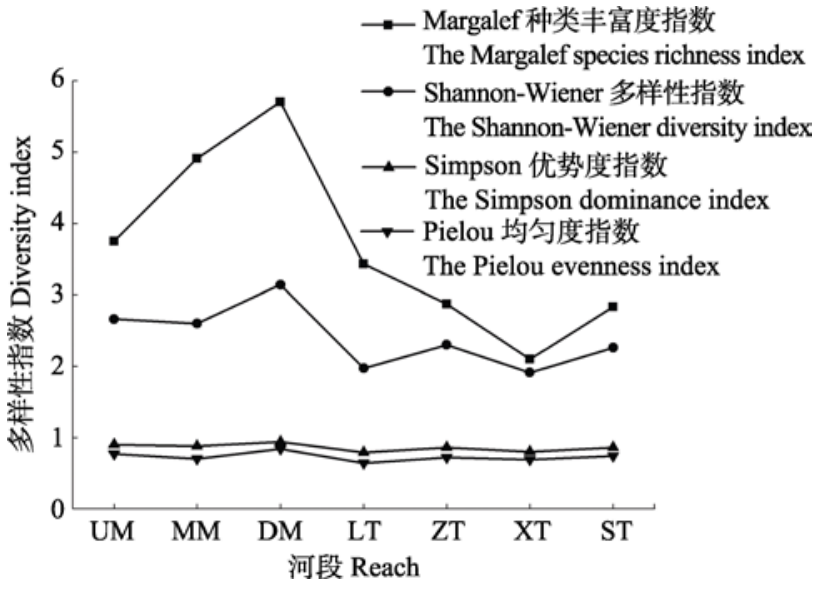

图2 南广河不同河段的鱼类多样性。UM: 上游(干流); MM: 中游(干流); DM: 下游(干流); LT: 洛亥河(支流); ZT: 镇舟 河(支流); XT: 巡司河(支流); ST: 宋江河(支流)。

Fig. 2 Fish diversity of different reaches in the Nanguang River. UM, Upstream (Mainstream); MM, Midstream (Mainstream); DM, Downstream (Mainstream); LT, Luohai River (Tributary); ZT, Zhenzhou River (Tributary); XT, Xunsi River (Tributary); ST, Songjiang River (Tributary).

镇舟河上游河段还分布有贝氏高原鱾及泉水鱼，而 在镇舟河上游大雪山镇(T3)河段还分布有少量齐口 裂腹鱼。广泛分布于宋江河、巡司河和镇舟河的小 型鱼类在洛亥河中分布较少, 仅采集到少量宽鯺 鱲、切尾拟鲿、红尾副鳅等, 而长薄鳅、薄鳅(Leptobotia pellegrini)、黑尾近红鮊(Ancherythroculter nigrocauda)、鲇鲤和短身金沙鳅(Jinshaia abbreviata) 等在该河段能采集到。

南广河3种濒危鱼类中鳗鲡仅在下游贾村(M14) 河段采集到，昆明裂腹鱼及鲈鲤均在支流洛亥河中 下游罗渡乡黄桷村(T2)河段采集到。易危物种中华 沙鲀、厚领鲂分布于干流下游河段; 齐口裂腹鱼在
干流上游源头河段、支流镇舟河上游源头河段及洛 亥河下游河段都有采集到; 岩原鲤在干流中游珙县 共腾村(M9)河段及洛亥河下游河段采集到; 白缘鮃 主要分布于干流中上游上罗(M8)至石碑乡(M5)河 段; 而长薄鳅仅在洛亥河下游河段采集到。长江上 游特有鱼类多分布于干、支流的中上游河段, 如短 体副鳅、华鲮(Bangana rendahli)、四川华吸鲀(Sinogastromyzon szechuanensis)和白缘鮃等，仅有四川 华鳊、半粲(Hemiculterella sauvagei)和黑尾粲 $(\mathrm{He}$ miculter tchangi)等少数几种特有鱼类分布于干流下 游河段(附录1)。

\section{3 讨论}

\section{1 南广河鱼类资源现状及变化趋势}

南广河历史上分布鱼类有 90 余种，本次调查采 集到鱼类64种, 物种数量明显减少, 但仍较为丰 富。与吴波等(2014)的调查结果(32种)相比，增加32 种，包括红尾副鳅、贝氏高原鳅和齐口裂腹鱼等分 布于南广河干流或支流上游的鱼类，草鱼(Ctenopharyngodon idella)、鲢、厚领鲂和乌鳢等分布于 下游至河口河段的中、小型经济鱼类，以及黑鯺鰁 (Sarcocheilichthys nigripinnis)、短须领须鮈 (Gnathopogon imberbis)、银鮈(Squalidus argentatus)和乐 山小鳔鮈等多种小型鱼类。调查区域及采样方法的 局限性应是之前的调查未采集到这些种类的主要 原因。结合《四川鱼类志》等文献资料及访问调查, 发现南广河历史上还曾分布有赤眼鳟(Squaliobarbus curriculus)、鳤(Ochetobius elongatus)、鳡(Elopichthys bambusa)、鳙(Hypophthalmichthys nobilis)、 
蒙古鲌(Chanodichthys mongolicus)、达氏鲌(C. dabryi)、四川白甲鱼(Onychostoma angustistomata)和瓣 结鱼(Folifer brevifilis)等鱼类, 但本次调查均未采 集到。鉴于本次调查比较系统, 调查范围涵盖了所 有干、支流，调查周期和持续时间较长，因而可以 推断这些未采集到的种类在南广河的种群数量可 能已极其稀少, 甚至绝迹。

南广河鱼类优势种组成较为单一, 只有宽鳍鱲 和鲤, 并且与常见种的IRI指数相差较大。一般来说, 在干扰因素较多的河流生境中, 优势种通常由一个 或少数几个种类组成(Cabral et al, 2001), 因此该流 域可能受到了较多外来因素的影响。南广河流域渔 获物以小型鱼类为主，超过 $50 \%$ 的优势种与常见种 均为小型鱼类, 中等经济鱼类在渔获物中的比例较 小, 多为偶见种。南广河的鱼类资源呈衰退趋势, 主要表现为体型较大的经济鱼类在渔获物中比例 下降、规格变小, 这与长江干流宜宾江段渔业资源 变化相一致(熊飞等, 2015)。众多水电站建设导致的 生境改变, 以及过度捕捞等可能是造成南广河鱼类 资源衰退的主要原因。

\section{2 南广河鱼类多样性及分布特点}

南广河干流下游至河口河段水体较深, 河道宽 阔, 饵料丰富, 且长江干流部分鱼类会上溯到月江 电站至河口河段进行产卵和索饵, 鱼类种类数及多 样性较高; 而上游河段水体较浅, 水流量小, 栖息 生境相对简单, 且由于梯级水电站的阻隔, 中、下 游鱼类无法上溯到上游河段, 因此鱼类种类数较 少、多样性较低。本次调查发现南广河的鱼类多样 性指数相对较高, 总体要高于雅砻江支流安宁河 (茹辉军等, 2016)、长江上游支流大宁河(杨峰等, 2013)等, 但低于长江上游保护区干流宜宾段(高天 街等, 2013)、岷江下游干流宜宾段(吕浩等, 2018)以 及赤水河(吴金明等, 2010)等, 主要原因可能为河流 自然生境差异以及人为干扰程度不同等。

南广河鱼类资源呈现出上游至中游增加, 中游 至下游降低的趋势。本次调查发现, 南广河干流中 游河段鱼类种类和数量都较为丰富, 下游河段虽种 类最为丰富, 但由于电站大坝的长期阻隔, 导致下 游河段多为深水库区, 样本采集受到一定影响, 且 下游至河口河段渔业捕捞强度较大, 因此调查期间 采集到的渔获物数量较少。南广河支流中, 中游的 镇舟河鱼类资源比较丰富, 与中下游支流巡司河、
宋江河相比, 该支流上大坝数量较少, 人为干扰程 度相对较小。

南广河流域不同河段的鱼类种类具有明显差 异, 干流下游一些电站的库区水体较深, 水面较宽, 一些喜静水、缓流水的鱼类如鲤、鲫、大眼䰻和尧 嘴鲌等成为该河段的主要种类。干流中上游以及支 流宋江河、镇舟河、巡司河中下游河段, 连续的小 型梯级水电站将河流分割成兼有流水、缓流水和静 水的多种栖息环境, 使喜流水和喜静水的一些小型 鱼类得以共存, 麦穗鱼、鲫、宽鯺鱲和乐山小鳔鮈 等成为主要分布的鱼类。而干流源头, 以及支流宋 江河、镇舟河上游和源头河段多急流和浅滩, 水温 较低, 底质多为乱石或卵石, 为一些喜流水、低温 的鱼类提供了适宜栖息的生境, 如贝氏高原鳅、泉 水鱼和齐口裂腹鱼等。支流洛亥河下游河段未修建 水电站, 河口与罗渡电站库区及库区上游相连, 河 流连通性较好, 适于长薄鲀、黑尾近红鮊和鲈鲤等 喜流水性鱼类生存, 且该河段两岸多石缝、石灰岩 溶洞, 溶洞洞口处水温较低, 分布于南广河干支流 上游的冷水鱼类如泉水鱼和齐口裂腹鱼等也在该 河段采集到。南广河鱼类物种的分布特点体现了鱼 类对于自然栖息生境差异的选择和适应性(费䩀慧 等, 2012)。

\section{3 南广河鱼类资源保护建议}

南广河作为长江右岸一级支流, 对维护长江流 域鱼类物种多样性具有重要作用。但是，该河流干、 支流上已建的水电站数量较多, 电站大坝导致河流 生境破碎化, 并在一定程度上阻碍了鱼类的迁移通 道, 可能造成了鱼类种类较历史记录大幅减少, 尤 其是一些具有迁移习性的鱼类, 目前只在下游至河 口段有少量分布。同时, 南广河流域的渔业捕捞强 度过大, 本次调查的渔获物以小型鱼类为主, 中等 及较大型鱼类占比较小。为保护南广河的鱼类多样 性, 逐步恢复其资源量, 提出以下保护建议: (1)加 强渔政监管, 加大保护宣传力度。控制捕捞强度和 捕捞规格, 严禁毒鱼、电鱼等非法捕捞方式, 严格 落实每年3-6月的禁渔期制度, 逐步提高渔民的保 护意识。(2)修复河道生境, 适时拆除部分小型闸坝。 南广河流域已建水电站较多, 为减缓其对鱼类迁移 的阻隔影响, 有必要修复河道的连通性, 特别是干 流上游及支流上一些小型电站因建设年代久远、库 区淤积等原因, 已经不再运行或基本丧失发电效益, 
应依据相关生态环境保护政策，对其进行拆除以恢 复河流连通性。(3)开展人工增殖放流。向南广河干、 支流放流一些珍稀、特有鱼类，以及具有重要经济 价值的种类，主要包括岩原鲤、鲈鲤、白甲鱼、华 鲮、中华倒刺鲃(Spinibarbus sinensis)、厚领鲂、长 吻鮠等，以增加其野外资源量。

致谢：四川大学生命科学学院的研究生吴波、文秦 超、邹茌、梁思倩、吴慧和李茂华等参加了部分野 外调查工作, 四川省宜宾市、高县、珙县、笏连县 等渔政管理部门对调查工作给予了大力支持, 在此 特别感谢!

\section{参考文献}

Cabral HN, Costa MJ, Salgado JP (2001) Does the Tagus estuary fish community reflect environmental changes? Climate Research, 18, 119-126.

Chen YY (1998) Fauna Sinica (Osteichthyes): Cypriniformes (II). Science Press, Beijing. (in Chinese) [陈宜瑜 (1998) 中国动物志 - 硬骨鱼纲 - 鲤形目 (中卷). 科学出版社, 北 京.]

Cheng JS, Yu LF (2004) The change of structure and diversity of demersal fish communities in the Yellow Sea and East China Sea in winter. Journal of Fisheries of China, 28, 29-34. (in Chinese with English abstract) [程济生, 俞连福 (2004) 黄、东海冬季底层鱼类群落结构及多样性变化. 水产学报, 28, 29-34.]

Chu XL, Zheng BS, Dai DY (1999) Fauna Sinica (Osteichthyes): Siluriforms. Science Press, Beijing. (in Chinese) [禇新洛, 郑葆珊, 戴定远 (1999) 中国动物志 - 硬骨鱼 纲・鲇形目. 科学出版社, 北京.]

Ding RH (1994) The Fishes of Sichuan. Sichuan Publishing House of Science and Technology, Chengdu. (in Chinese) [丁瑞华 (1994) 四川鱼类志. 四川科学技术出版社, 成 都.]

Fei JH, Wang XZ, Shao XY (2012) Spatial pattern of fish community in the Erhai Lake. Journal of Fisheries of China, 36, 1225-1233. (in Chinese with English abstract) [费䩀慧, 汪兴中, 邵晓阳 (2012) 洱海鱼类群落的空间分布格局. 水产学报, 36, 1225-1233.]

Gao TH, Tian HW, Ye C, Duan XB (2013) Diversity and composition of fish in the mainstream of National Nature Reserve of Rare and Endemic Fish in the Upper Yangtze River. Freshwater Fisheries, 43, 36-42. (in Chinese with English abstract) [高天珩, 田辉伍, 叶超, 段辛斌 (2013) 长江上游珍稀特有鱼类国家级自然保护区干流段鱼类组 成及其多样性. 淡水渔业, 43, 36-42.]

Jiang ZG, Jiang JP, Wang YZ, Zhang E, Zhang YY, Li LL, Xie F, Cai B, Cao L, Zheng GM, Dong L, Zhang ZW, Ding P,
Luo ZH, Ding CQ, Ma ZJ, Tang SH, Cao WX, Li CW, Hu HJ, Ma Y, Wu Y, Wang YX, Zhou KY, Liu SY, Chen YY, Li JT, Feng ZJ, Wang Y, Wang B, Li C, Song XL, Cai L, Zang CX, Zeng Y, Meng ZB, Fang HX, Ping XG (2016) Red List of China's Vertebrates. Biodiversity Science, 24, 500-551. (in Chinese and in English) [蒋志刚, 江建平, 王 跃招, 张鹗, 张雁云, 李立立, 谢锋, 蔡波, 曹亮, 郑光 美, 董路, 张正旺, 丁平, 罗振华, 丁长青, 马志军, 汤宋 华, 曹文宣, 李春旺, 胡慧建, 马勇, 吴毅, 王应祥, 周开 亚, 刘少英, 陈跃英, 李家堂, 冯祚建, 王燕, 王斌, 李 成, 宋雪琳, 蔡蕾, 蔵春金金, 曾岩, 孟智斌, 方红霞, 平晓 鸽 (2016) 中国脊椎动物红色名录. 生物多样性, 24, 500-551.]

Kottelat M (2013) The fishes of the inland waters of Southeast Asia: A catalogue and core bibliography of the fishes known to occur in freshwaters, mangroves and estuaries. The Raffles Bulletin of Zoology, 27, 1-663.

Lü H, Tian HW, Duan XB, Chen DQ, Shen SY, Liu SP (2018) Analysis of fish resources status and diversity in the lower reaches of the Minjiang River. Resources and Environment in the Yangtze Basin, 27, 88-96. (in Chinese with English abstract) [吕浩, 田辉伍, 段辛斌, 陈大庆, 申绍祎, 刘绍 平 (2018) 岷江下游干流段鱼类资源现状及其多样性分 析. 长江流域资源与环境, 27, 88-96.]

Margalef R (1958) Information theory in biology. General Systems Yearbook, 3, 36-71.

Pielou EC (1975) Ecological Diversity. John Wiley and Sons, New York.

Pinkas L, Oliphant MS, Iverson ILK (1971) Food habits of albacore, bluefin tuna, and bonito in California waters. Fish Bulletin, 152, 1-105.

Ru HJ, Zhang Y, Li YF, Wang HM, Shen ZW, Wu XX, Li R, Sheng Q, Ni ZH (2016) Community composition and status of fish resources in Anning River. Journal of Hydroecology, 37, 68-74. (in Chinese with English abstract) [茹辉军, 张 燕, 李云峰, 王红梅, 沈子伟, 吴湘香, 李荣, 盛强, 倪朝 辉 (2016) 雅䶭江支流安宁河鱼类群落组成及资源现状. 水生态学杂志, 37, 68-74.]

Shannon CE, Wiener W (1949) The Mathematical Theory of Communication. University of Illinois Press, Urbana.

Simpson EH (1949) Measurement of diversity. Nature, 163, 688.

Wu B, Wang Y, Zhou B, Song ZB (2014) Status of fish resources in the Nanguang River in Sichuan Province. Sichuan Journal of Zoology, 33, 460-465. (in Chinese with English abstract) [吴波，王芗，周波，宋昭彬 (2014) 四川南广河 的鱼类. 四川动物, 33, 460-465.]

Wu JM, Zhao HT, Miao ZG, Chen YX, Zhang FT, Wang JW (2010) Status and conservation of fish resources in the Chishui River. Biodiversity Science, 18, 162-172. (in Chinese with English abstract) [吴金明, 赵海涛, 苗志国, 陈永祥, 张富铁, 王剑伟 (2010) 赤水河鱼类资源的现状与保护. 生物多样性, 18, 162-172.] 
Xiong F, Liu HY, Duan XB, Liu SP, Chen DQ (2014) Community structure of fish and resources utilization in Jiangjin section of the upper Yangtze River. Journal of Anhui University (Natural Science Edition), 38, 94-102. (in Chinese with English abstract) [熊飞, 刘红艳, 段辛斌, 刘绍平, 陈 大庆 (2014) 长江上游江津江段鱼类群落结构及资源利 用. 安徽大学学报(自然科学版), 38, 94-102.]

Xiong F, Liu HY, Duan XB, Liu SP, Chen DQ (2015) Present status of fishery resources in Yibin Section of the Upper Yangtze River. Journal of Southwest University (Natural Science Edition), 37, 43-50. (in Chinese with English abstract) [熊飞, 刘红艳, 段辛斌, 刘绍平, 陈大庆 (2015) 长 江上游宜宾江段渔业资源现状研究. 西南大学学报(自然 科学版), 37, 43-50.]

Yang F, Yao WZ, Deng HT, Chen DQ, Liu SP, Duan XB (2013) The current situation of fish resources in the Daning River after the impoundment of the Three Gorges Reservoir. Freshwater Fisheries, 43, 51-52, 56-57. (in Chinese with
English abstract) [杨峰, 姚维志, 邓华堂, 陈大庆, 刘绍 平, 段辛斌 (2013) 三峡库区蓄水后大宁河鱼类资源现 状研究. 淡水渔业, 43, 51-52, 56-57.]

Yibin City Chronicles Compilation Committee (2010) Yibin City Chronicles: 1911-2000 (I). Zhong Hua Book Company, Beijing. (in Chinese) [宜宾市志编纂委员会 (2010) 宜宾市 志: 1911-2000 (上). 中华书局, 北京.]

Yuan JL, Zhu JJ, Zhang AJ (2009) Effective calculation and protected countermeasures of Qincun Reservoir Dam construction to the fish resources. Journal of Hydroecology, 30, 123-127. (in Chinese with English abstract) [原居林, 朱俊 杰, 张爱菊 (2009) 钦寸水库大坝建设对鱼类资源的影 响预测及其保护对策. 水生态学杂志, 30, 123-127.]

Yue PQ (2000) Fauna Sinica (Osteichthyes): Cypriniformes (III). Science Press, Beijing. (in Chinese) [乐佩琦 (2000) 中国 动物志 - 硬骨鱼纲・ 鲤形目(下卷). 科学出版社, 北京.]

(责任编委：陈小勇 责任编辑：问文杰)

\section{附录 Supplementary Material}

附录1 南广河鱼类名录

Appendix 1 Fish species in the Nanguang River

http://www.biodiversity-science.net/fileup/PDF/2019264-1.pdf 
代梦梦, 杨坤, 黎树, 王小东, 宋昭涁. 长江上游支流南广河的鱼类多样性及资源现状. 生物多样性, 2019, 27 (10): 1081-1089.

http://www.biodiversity-science.net/CN/10.17520/biods.2019264

附录1 南广河鱼类名录

Appendix 1 Fish species in the Nanguang River

\begin{tabular}{|c|c|c|c|c|c|c|c|c|}
\hline \multirow{2}{*}{$\begin{array}{c}\text { 种类 } \\
\text { Species }\end{array}$} & \multirow{2}{*}{$\begin{array}{c}\text { 保护现状 } \\
\text { Conservation status }\end{array}$} & \multicolumn{3}{|c|}{ 干流 Mainstream } & \multicolumn{4}{|c|}{ 支流 Tributary } \\
\hline & & $\begin{array}{c}\text { 上游 } \\
\text { Upstream }\end{array}$ & $\begin{array}{c}\text { 中游 } \\
\text { Midstream }\end{array}$ & $\begin{array}{c}\text { 下游 } \\
\text { Downstream }\end{array}$ & $\begin{array}{c}\text { 洛亥河 } \\
\text { Luohai River }\end{array}$ & $\begin{array}{c}\text { 镇舟河 } \\
\text { Zhenzhou River }\end{array}$ & $\begin{array}{c}\text { 巡司河 } \\
\text { Xunsi River }\end{array}$ & $\begin{array}{c}\text { 宋江河 } \\
\text { Songjiang River }\end{array}$ \\
\hline $\begin{array}{l}\text { I 鳗鲡目 Anguilliformes } \\
\text { (一)鳃鲡科 Anguillidae }\end{array}$ & & & & & & & & \\
\hline $\begin{array}{l}\text { 1.鳗鲡 Anguilla japonica } \\
\text { II 鲤形目 Cypriniformes } \\
\text { (二)条鳅科 Nemacheilidae }\end{array}$ & EN & & & + & & & & \\
\hline 2. 红尾副鳅 Homatula variegata & & + & + & & + & + & + & + \\
\hline 3.短体副鳅 Homatula potanini* & & + & + & & & + & + & + \\
\hline $\begin{array}{l}\text { 4.贝氏高原鱾 Triplophysa bleekeri } \\
\text { (三)鲀科 Cobitidae }\end{array}$ & & + & & & & + & & + \\
\hline 5.中华沙鳅 Sinibotia superciliaris & $\mathrm{VU}$ & + & + & + & + & & & \\
\hline 6.长薄鳅 Leptobotia elongata* & VU & & & & + & & & \\
\hline 7.薄鳅 Leptobotia pellegrini & & & & & + & & & \\
\hline 8.泥鳅 Misgurnus anguillicaudatus & & + & + & + & & + & + & + \\
\hline $\begin{array}{l}\text { 9. 大鳞副泥鳅 Paramisgurnus dabryanus } \\
\text { (四)鲤科 Cyprinidae }\end{array}$ & & + & + & + & & + & + & \\
\hline 10.宽鳍鱲 Zacco platypus & & + & + & + & + & + & + & + \\
\hline 11.马口鱼 Opsariichthys bidens & & + & + & + & & + & + & + \\
\hline 12.草鱼 Ctenopharyngodon idella & & & + & + & & & & \\
\hline 13.鲢 Hypophthalmichthys molitrix & & & & + & & & & \\
\hline 14.高体鳑鲏 Rhodeus ocellatus & & + & + & + & & + & + & + \\
\hline 15.四川华鳊 Sinibrama taeniatus* & & & & + & & & & \\
\hline
\end{tabular}


代梦梦, 杨坤, 黎树, 王小东, 宋昭涁. 长江上游支流南广河的鱼类多样性及资源现状. 生物多样性, 2019, 27 (10): 1081-1089. http://www.biodiversity-science.net/CN/10.17520/biods.2019264

16.高体近红鮊 Ancherythroculter kurematsui*

17.黑尾近红鮊 Ancherythroculter nigrocauda*

18.半粲 Hemiculterella sauvage $i^{*}$

19.羧 Hemiculter leucisculus

20.黑尾粲 Hemiculter tchangi*

21.翅嘴鮊 Culter alburnus

22. 厚领鲂 Megalobrama pellegrini*

VU

23.唇䱉 Hemibarbus labeo

24.花䱻 Hemibarbus maculatus

25.麦穗鱼 Pseudorasbora parva

26. 黑鯺鰁 Sarcocheilichthys nigripinnis

27.短须领须鮈 Gnathopogon imberbis

28. 银鮈 Squalidus argentatus

29.点纹银鮈 Squalidus wolterstorff

30.棒花鱼 Abbottina rivularis

31.钝吻棒花鱼 Abbottina obtusirostris*

32.乐山小鯂鮈 Microphysogobio kiatingensis

33.蛇鮈 Saurogobio dabryi

34.中华倒刺鲃 Spinibarbus sinensis

35.鲇鲤 Percocypris pingi*

EN, PP

36.云南光唇鱼 Acrossocheilus yunnanensis

37. 白甲鱼 Onychostoma simum

38.华鲮 Bangana rendahli*

39.泉水鱼 Pseudogyrinocheilus prochilus

40.墨头鱼 Garra imberba

41.齐口裂腹鱼 Schizothorax prenanti* 
代梦梦, 杨坤, 黎树, 王小东, 宋昭森. 长江上游支流南广河的鱼类多样性及资源现状. 生物多样性, 2019, 27 (10): 1081-1089. http://www.biodiversity-science.net/CN/10.17520/biods.2019264

42. 昆明裂腹鱼 Schizothorax grahami*

43.岩原鲤 Procypris rabaudi*

44.鲤 Cyprinus carpio

45. 鲫 Carassius auratus

(五)爬鳅科 Balitoridae

46.短身金沙鳅 Jinshaia abbreviata*

47.四川华吸鳅 Sinogastromyzon szechuanensis*

48. 西昌华吸鳅 Sinogastromyzon sichangensis*

III 鲇形目 Siluriformes

(六)鲇科 Siluridae

49.鲇 Silurus asotus

50.南方鲇 Silurus meridionalis

(七)魭科 Bagridae

51. 黄滪鱼 Tachysurus fulvidraco

52.瓦氏黄颡鱼 Tachysurus vachellii

53. 光泽黄滪鱼 Tachysurus nitidus

54.长吻鮠 Tachysurus dumerili

55.粗唇鮸 Tachysurus crassilabris

56.切尾拟鲿 Tachysurus truncatus

57.短尾拟魭 Tachysurus brevicaudatus

58. 大鰙鳠 Hemibagrus macropterus

(八)针头鮠科 Amblycipitidae

59.白缘鮃 Liobagrus marginatus

(九)鮡科 Sisoridae

60.福建纹胸鮡 Glyptothorax fokiensi

IV 合鳃鱼目 Synbgranchiformes
EN

VU, PP

$$
+
$$


代梦梦, 杨坤, 黎树, 王小东, 宋昭涁. 长江上游支流南广河的鱼类多样性及资源现状. 生物多样性, 2019, 27 (10): 1081-1089. http://www.biodiversity-science.net/CN/10.17520/biods.2019264

(十)合鰓鱼科 Synbranchidae

61.黄鳝 Monopterus albus

$\mathrm{V}$ 鲇形目 Perciformes

(十一)真鲇科 Percichthyidae

62.大眼鱖 Siniperca knerii

$+$

(十二)鰕虎鱼科 Gobiidae

63. 子陵吻鰕虎鱼 Rhinogobius giurinus

(十三)鳢科 Channida

64.乌鳢 Channa argus

\section{* 长江上游特有鱼类; $\mathrm{EN}$ : 濒危物种; VU: 易危物种; PP: 四川省重点保护鱼类。}

* Species endemic to the upper Yangtze River; EN, Endangered species; VU, Vulnerable species; PP, Protected fish species in Sichuan Province. 